\title{
JOGOS DE GEOTECNOLOGIA PARA O ENSINO DE ESTUDOS AMBIENTAIS NO AMBIENTE ESCOLAR: EXPERIÊNCIA DE SANTARÉM (PA)
}

Tatiana Lobato de Magalhaes ${ }^{1}$

Resumo: $O$ uso de geotecnologias para o estudo ambiental vem se consolidando com o passar dos anos, porém, no âmbito escolar, isto ainda não é a realidade brasileira. O objetivo deste estudo foi introduzir conceitos de cartografia e do uso de geotecnologias nos estudos ambientais, para alunos da rede pública de ensino e abordar a importância da conservação do meio ambiente. Foram elaborados dois jogos de geoprocessamento, com a temática água e floresta: 1. Memória de geotecnologias, 2. Série histórica de imagens de satélite. Os jogos de geoprocessamento se mostraram uma metodologia adequada no ensino de geotecnologias para estudos ambientais. Além de ser uma metodologia de baixo custo de implantação e com boa aceitação entre professores e alunos.

Palavras-chave: Cartografia; Geoprocessamento; Série Histórica; Landsat; Metodologia Alternativa. 


\section{Introdução}

O ensino da geografia estuda a relação do 'homem e a natureza', neste contexto, a geotecnologia contribui de maneira significativa para a difusão da educação ambiental (SILVA; RODRIGUEZ, 2014). O uso de geotecnologias nos estudos ambientais vem se consolidando com o passar dos anos e, atualmente, os estudos ambientais são sempre auxiliados por especialistas em cartografia e sensoriamento remoto. Progressivamente, a geotecnologia vem contribuindo para o avanço do ensino escolar (SILVA, 2013). Para Wrublack et al. (2014) o conhecimento de geotecnologia deve ser utilizado como uma ferramenta didática na educação ambiental. Nesse sentido, algumas iniciativas têm sido desenvolvidas no âmbito escolar, contudo, essa ainda não é uma realidade palpável na rede de ensino público brasileira (ANDRADES-FILHO; RIBEIRO, 2014). Correa; Fernandes; Paini (2010) relatam que, em geral, as escolas dispõem de computadores, mas não tem uma metodologia adequada para o ensino da geoinformação. De acordo com Silva (2013), os objetos e metodologia, utilizados na prática de ensino escolar, deveriam ir além da simples transmissão de conhecimentos cartográficos por meio da apresentação de mapas. Silva \& Rodriguez (2014) defendem a importância da busca de novos "caminhos metodológicos", com uma perspectiva interdisciplinar, para os estudos do espaço geográfico.

O município de Santarém, Oeste do Pará, é um local interessante para se falar de estudos ambientais. Esse município amazônico está localizado no encontro das águas de dois grandes rios, o Rio Amazonas e o Rio Tapajós. Além da importância dos recursos hídricos locais, essa região vem sofrendo uma forte pressão antrópica. É uma zona de fronteira agrícola, em plena expansão das atividades agropecuárias, o que fortalece à fragilidade para a conservação da floresta Amazônica nessa região.

Visando auxiliar o desenvolvimento e o interesse de alunos da rede pública de ensino para a geotecnologia, foi idealizada essa metodologia, envolvendo jogos de geoprocessamento aplicados aos estudos ambientais. Nesse intuito, foi proposto o lançamento de um projeto tendo como público alvo alunos da rede ensino pública, no município de Santarém. O projeto "Jogos de geoprocessamento no ensino de estudos ambientais" tem como objetivos: Introduzir conceitos de cartografia e de geoprocessamento, ensinar a importância do uso de informações espaciais (mapas, imagens de satélite, série histórico, GPS) aplicados aos estudos ambientais e também abordar a importância da conservação do meio ambiente.

\section{Material e métodos}

A área de abrangência do projeto englobou escolas da rede municipal de ensino no município de Santarém, totalizando 64 escolas municipais na área urbana. O projeto foi elaborado com caráter contínuo e, para a sua realização, foi proposta uma parceria entre a Secretaria Municipal de Educação (SEMED) e a Secretaria Municipal de Meio Ambiente (SEMMA). O Centro de Informação 
e Educação Ambiental (CIAM), vinculado a SEMMA, atuou como idealizador e coordenador do projeto.

As atividades tiveram frequência quinzenal e foram sediadas no CIAM, acontecendo em um espaço denominado por "Salão das Águas". A faixa etária escolhida foi de alunos do quinto ano (nove anos de idade), por ser uma idade em que os alunos já tiveram alguma iniciação aos conhecimentos geográficos. As escolas foram contatadas pela SEMED, as turmas recebidas no CIAM foram acompanhadas pelos respectivos professores. As turmas contaram com até 30 alunos, não sendo excedido este número, devido a limitações de espaço e condições de atendimento pela equipe do CIAM. O tempo total estimado para a aplicação da didática foi de duas horas.

O projeto foi delineado com a proposta de um orçamento de baixo custo, a fim de poder ser replicado para outros municípios, sem gerar ônus para as secretarias municipais de educação e de meio ambiente. A metodologia utilizada foi bastante simplista e visou promover um conhecimento básico de geotecnologias e sua aplicação nos estudos ambientais, respeitando os limites e a capacidade de comunicação das crianças. Foram escolhidas duas temáticas, coerentes com o panorama do município de Santarém, que são: água e floresta. A didática proposta foi dividida em cinco etapas (Figura 1), iniciando com a apresentação de conceitos teóricos e finalizando com uma visita guiada dos estudantes ao Centro de Informação e Educação Ambiental.

\begin{tabular}{|c|c|c|c|c|c|}
\cline { 2 - 4 } $\begin{array}{c}\text { Conceitos } \\
\text { teóricos: } \\
\text { visualização de } \\
\text { mapas }\end{array}$ & $\begin{array}{c}\text { Memória de } \\
\text { geotecnologias }\end{array}$ & $\begin{array}{c}\text { Sériérica } \\
\text { de imagens de } \\
\text { satélite: } \\
\text { Landsat }\end{array}$ & $\begin{array}{c}\text { Programas de } \\
\text { geoprocessamento: } \\
\text { conhecendo sua } \\
\text { cidade }\end{array}$ & $\begin{array}{c}\text { Visita guiada ao } \\
\text { centro de } \\
\text { informações e } \\
\text { educação ambiental }\end{array}$ \\
\hline
\end{tabular}

Figura 1: Diagrama das etapas didáticas envolvidas na metodologia proposta.

Fonte: De autoria própria.

Os recursos utilizados (Tabela 1, próxima página) foram basicamente: um mapa, um computador e os jogos de geoprocessamento (confeccionados de maneira manual e com baixo custo financeiro). O computador utilizado contava com o programa QGIS (2016), disponível para download e de uso livre. Os arquivos shapefile utilizados foram de uso livre e adquiridos no site do Instituto Brasileiro de Geografia e Estatística (IBGE, 2016).

Visando atingir escolas municipais da rede de ensino público, o projeto foi elaborado com baixo custo de implantação. Para tal, foi desconsiderada a aquisição de um computador específico para essa atividade (já que este pode ser emprestado de qualquer outro setor da prefeitura ou da escola) e utilizando informações cartográficas de uso livre (Tabela 2, próxima página). 
Tabela 1: Recursos utilizados na didática de geoprocessamento.

\begin{tabular}{lll}
\hline \multicolumn{1}{c}{ ITEM } & $\mathbf{N}^{\circ}$ & \multicolumn{2}{c}{ OBSERVAÇÕES } \\
\hline Computador & 1 & $\begin{array}{l}\text { Configuração básica e tela de 19 } \\
\text { polegadas }\end{array}$ \\
\hline Jogo memória de geotecnologias & 2 & $\begin{array}{l}\text { Impresso em papel fotográfico e } \\
\text { colado em placas de madeira ou } \\
\text { Eucatex }\end{array}$ \\
\hline Jogo das séries históricas de imagens Landsat & 4 & $\begin{array}{l}\text { impresso em papel fotográfico e } \\
\text { colado em placas de madeira ou } \\
\text { Eucatex }\end{array}$ \\
\hline Mapa & 1 & $\begin{array}{l}\text { Mapa em tamanho A1, } \\
\text { representando a cidade de } \\
\text { Santarém }\end{array}$ \\
\hline Arquivo shapefile: cidade, estado e país & 1 & Download no site do IBGE \\
\hline Instalação do QGIS & 1 & Download no site do QGIS \\
\hline Imagens de satélite Landsat & 5 & Download no site do USGS \\
\hline
\end{tabular}

Fonte: De autoria própria.

Tabela 2: Estimativa do custo de implantação.

\begin{tabular}{lllc}
\hline \multicolumn{1}{c}{ DESCRIÇÃo } & \multicolumn{1}{c}{ MATERIAL NECESSÁRIO } & $\begin{array}{c}\text { CUSTO ESTIMADO } \\
\text { (REAIS) }\end{array}$ \\
\hline $\begin{array}{l}\text { Impressão colorida em papel } \\
\text { fotográfico }\end{array}$ & 8 folhas A4 de papel fotográfico & 16,00 \\
\hline $\begin{array}{l}\text { Impressão colorida em papel } \\
\text { branco }\end{array}$ & 20 folhas de papel A4 tipo sulfite & 20,00 \\
\hline Placa de Eucatex & & 20,00 \\
\hline Papel adesivo transparente & $1,5 \mathrm{~m}^{2}$ & 10,00 \\
\hline Mapa impresso em lona & $1 \mathrm{~m}^{2}$ de papel tipo contact & 60,00 \\
\hline Programa QGIS & Uso livre & - \\
\hline Shapefile & $\begin{array}{l}\text { Vetor de cidade, estado e país; } \\
\text { uso livre }\end{array}$ & - \\
\hline Imagens Landsat & $\begin{array}{l}4 \text { imagens de diferentes anos; } \\
\text { uso livre }\end{array}$ \\
\hline
\end{tabular}

Custo Total Estimado

Fonte: De autoria própria.

$R \$ 126,00$

A primeira etapa "Conceitos teóricos: visualização de mapas" consistiu na apresentação do assunto utilizando um mapa da cidade de Santarém (tamanho A1, impresso em lona). Os conceitos teóricos apresentados foram relacionados com as palavras utilizadas no jogo de "Memória de geotecnologias" e com os conhecimentos de geografia que os alunos obtiveram anteriormente, nas suas aulas na rede de ensino público. Essa etapa foi figurada por uma conversa interativa entre o interlocutor e as crianças, com o objetivo de conectar as crianças com o mundo das geotecnologias. Seguido da primeira etapa, se iniciaram os jogos de geoprocessamento, primeiramente foi aplicado a "Memória de geotecnologias", onde foi reforçado o vocabulário de geotecnologias (Figura 2). O jogo "Memória de geotecnologias" foi impresso em papel fotográfico e colado em placas de Eucatex de 7 por $7 \mathrm{~cm}$, totalizando 44 peças.

Revbea, São Paulo, V.11, № 2: 313-323, 2016. 


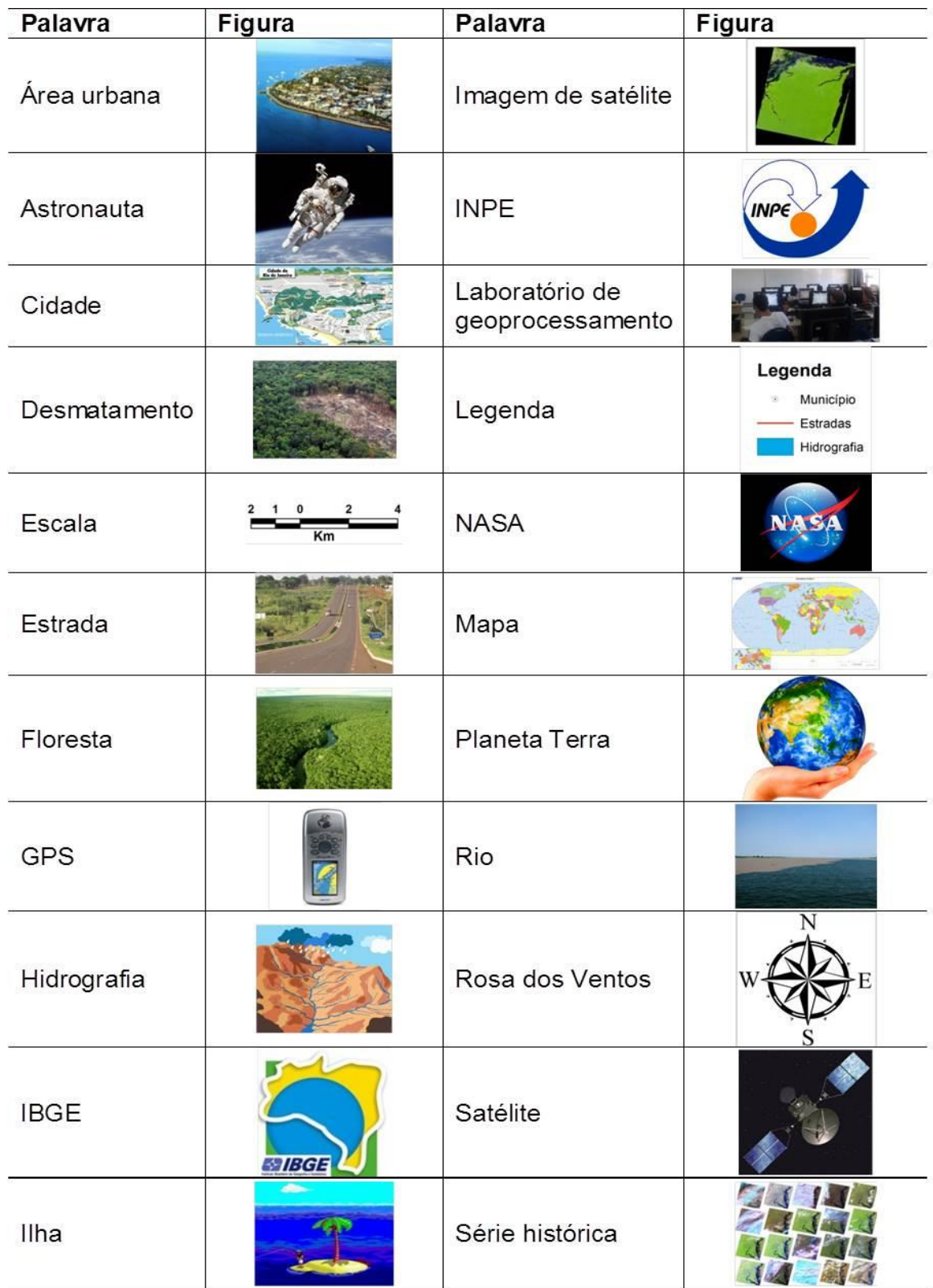

Figura 2: Exemplo das palavras e figuras utilizadas no jogo "Memória de geotecnologias". Fonte: De autoria própria.

$\mathrm{Na}$ terceira etapa, foram aplicados os jogos de geoprocessamento "Série histórica de imagens de satélite: Landsat", onde as crianças puderam elaborar por elas mesmas, a construção de séries históricas organizando este objeto de estudo ambiental. Foram utilizadas imagens Landsat 5 e Landsat 8, cena 227/62 (Earthexplorer, 2016), nas composições RGB 543 e 654, respectivamente. As séries históricas foram compostas pelos anos 2008, 2009, 2010 (imagens Landsat 5), 2013 e 2014 (imagens Landsat 8) e representaram quatro cenários no município de Santarém (Figura 3). Na temática "água" foram apresentados dois exemplos, um com formação de ilhas no Rio Amazonas e outro com a dinâmica da modificação de ilhas em frente à cidade de Santarém, 
em pleno encontro dos rios Amazonas e Tapajós. Na temática "floresta", dois exemplos de desmatamento foram apresentados, o primeiro em área urbana (construção de loteamentos para moradia) e o segundo em área de rural (conversão de florestas em área de agricultura). O jogo "Série histórica de imagens de satélite: Landsat' foi impresso em papel simples e recoberto com papel plastificado adesivo, em placas de Eucatex com 21 por $21 \mathrm{~cm}$, totalizando 20 quadros.

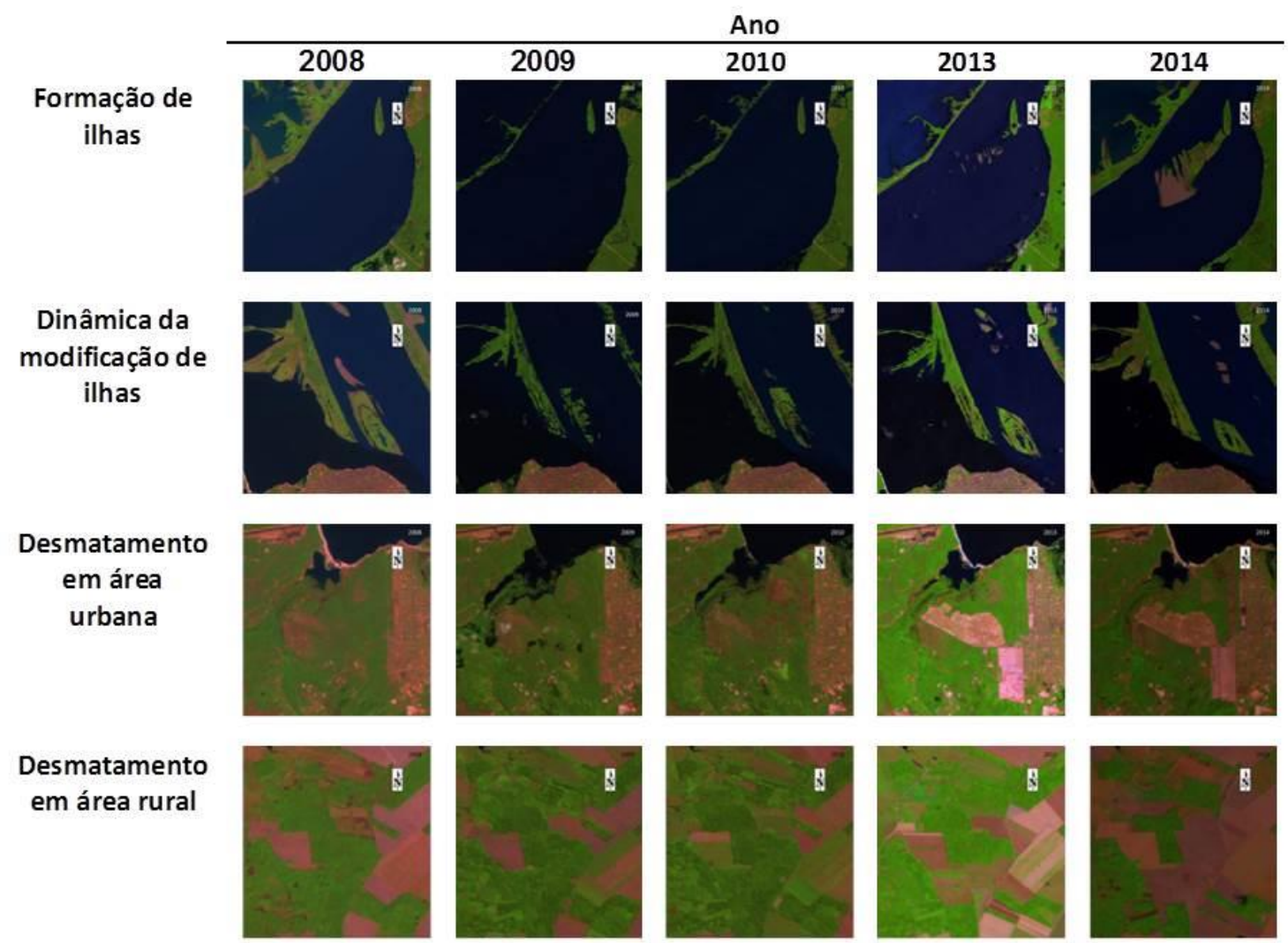

Figura 3: Exemplo dos quadros utilizados no jogo de geoprocessamento para a construção de séries históricas de imagens de satélite Landsat.

Fonte: De autoria própria. Adaptado de EARTHEXPLORER (2016).

Primeiramente, os alunos organizaram os quadros em ordem cronológica (2008 - 2009 - 2010 - 2013 - 2014), e posteriormente analisaram as mudanças que ocorreram entre estes anos. A didática apresentada é similar ao que os cientistas fazem para analisar as alterações ambientais ao longo dos anos, por meio de interpretação visual de imagens orbitais. Na quarta etapa, "Programa de geoprocessamento QGIS", foi apresentado o programa aos alunos, sendo demonstrado o perímetro do município de Santarém, do estado do Pará e posteriormente o perímetro do Brasil. Os objetivos dessa etapa foram apresentar um programa de geoprocessamento, amplamente utilizado no meio científico, para estudos ambientais. Além disso, o objetivo foi apresentar o formato do município - estado - país, em que vivem, demonstrando as dimensões e distâncias entre cada um. Essa etapa foi finalizada com um 
reforço dos conceitos sobre o território, a importância dos estudos do IBGE e da conservação do meio ambiente.

A arte gráfica para os jogos de geoprocessamento foi elaborada por um técnico de geoprocessamento do CIAM e foi disponibilizada para os técnicos de educação da rede de ensino público do município de Santarém. Na etapa final, os alunos foram convidados a conhecer o "Laboratório de Geoprocessamento do CIAM", em uma visita guiada pelo centro.

\section{Resultados e discussão}

Os jogos de geoprocessamento (Figura 4) obtiveram uma boa aceitação por parte dos professores e dos alunos. Foi observado que, os alunos tiveram a oportunidade aprender os conhecimentos básicos teóricos de cartografia, e tiveram um contato inicial com programas de geoprocessamento, além do uso de geotecnologias aplicado em estudos ambientais.

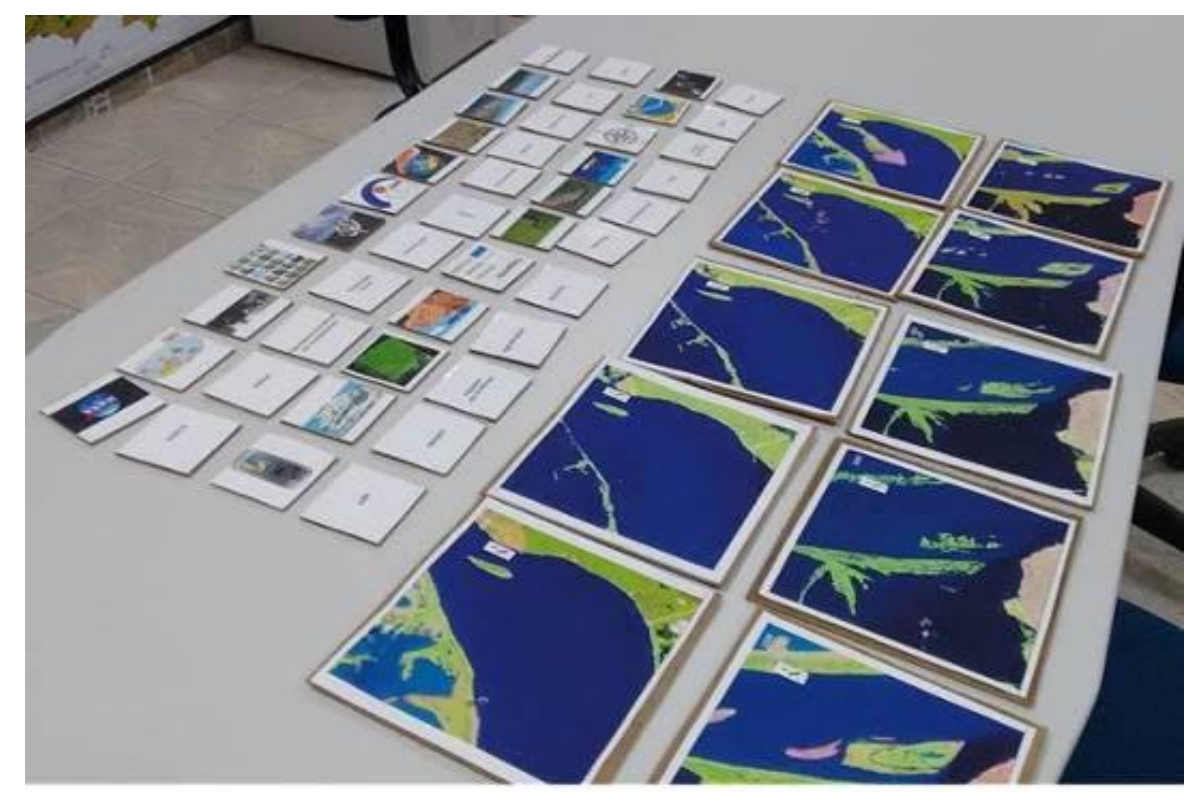

Figura 4: Jogos de geoprocessamento. Fonte: De autoria própria.

Os conceitos de cartografia apresentados na primeira etapa (teórica), foram reforçados na segunda etapa (prática), onde foi aplicado o jogo "Memória de geotecnologias" (Figura 5). Os alunos apresentaram particular interesse por esse jogo, pois praticamente todas as palavras foram "novas" para eles. Correa; Fernandes; Paini (2010) relatam que 90\% dos alunos entrevistados (no estudo realizado por estes autores), em rede pública e privada de ensino, não conhecem conceitos básicos de geotecnologias, como o termo GPS (global position system), por exemplo. 


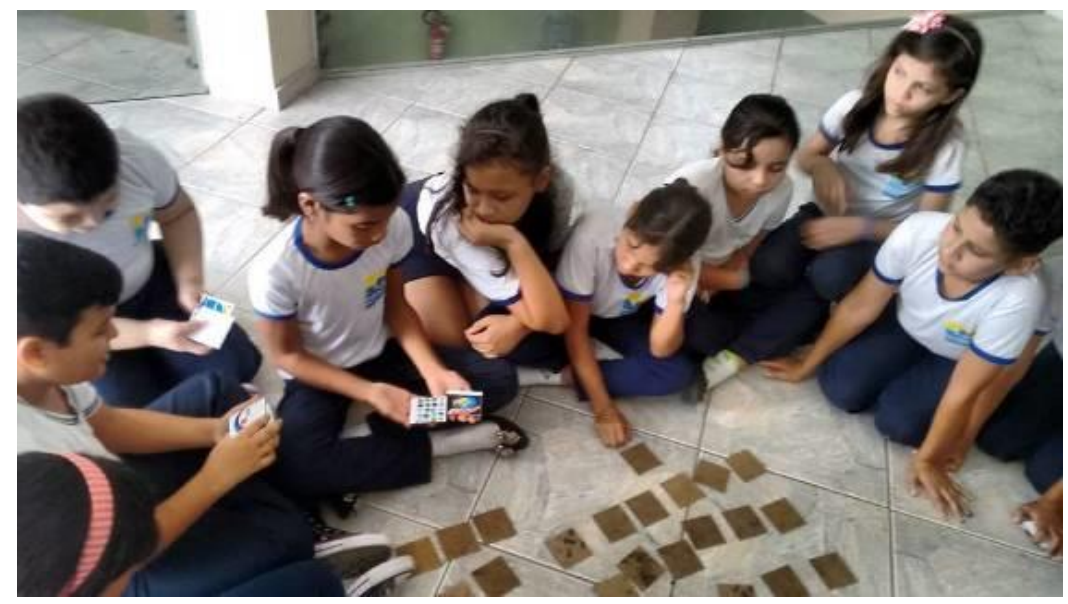

Figura 5: Alunos da Escola Fluminense brincando com o jogo de geoprocessamento "Memória de geotecnologias".

Fonte: De autoria própria.

Na terceira etapa, os alunos puderam "experimentar" como cientistas em seus estudos ambientais. Eles analisaram duas temáticas de modificações ambientais: 1. Monitoramento de uma mudança natural no meio ambiente: formação de ilhas (Figura 6-A, próxima página); 2. Monitoramento da ação antrópica sobre o meio ambiente: desmatamento (Figura 6-B, próxima página). Wrublack et al. (2014) reportam que, nos dias atuais, o desmatamento é uma das principais preocupações ambientais da sociedade. A geotecnologia está conectada a necessidade de se ter uma visão espacial dos fenômenos e alterações da natureza (SILVA, 2013). Os jogos de geoprocessamento, como a "Série histórica de imagens de satélite: Landsat", vêm a contribuir para que os alunos possam observar essas alterações e fenômenos da natureza.

Essa etapa da metodologia de ensino de geotecnologias foi bastante interessante, pois ela desenvolve a capacidade dos alunos de organizar as informações, observar as evidencias e também fazer/responder, perguntas sobre o meio ambiente. A "Série histórica de imagens de satélite: Landsat" absorve boa parte da metodologia científica que é utilizada pelos pesquisadores. $O$ desenvolvido do olhar reflexivo sobre o meio ambiente é importante desde as fases iniciais, até a vida adulta. A perspectiva espacial e temporal auxiliam o processo de ensino e formação de opinião crítica, além de proporcionar a interatividade entre alunos, professores e imagens de espaciais (ANDRADES-FILHO; RIBEIRO, 2014). O uso de jogos de geoprocessamento auxilia esse aprendizado de uma maneira divertida e educativa, já que os alunos podem aprender a fazer estudos ambientais brincando (Figura 7, próxima página). Silva (2013) defende que, é importante apresentar os conceitos cartográficos aos alunos de uma maneira reflexiva e crítica, para de fato desenvolver um processo de ensino-aprendizagem. Também é relevante possibilitar aos alunos o conhecimento crítico e a valorização da educação, seja ela cartográfica ou não. Já Silva e Rodriguez (2014), abordam a importância de que, é vital desenvolver uma visão holística e interdisciplinar, para os estudos de geografia e meio ambiente. 

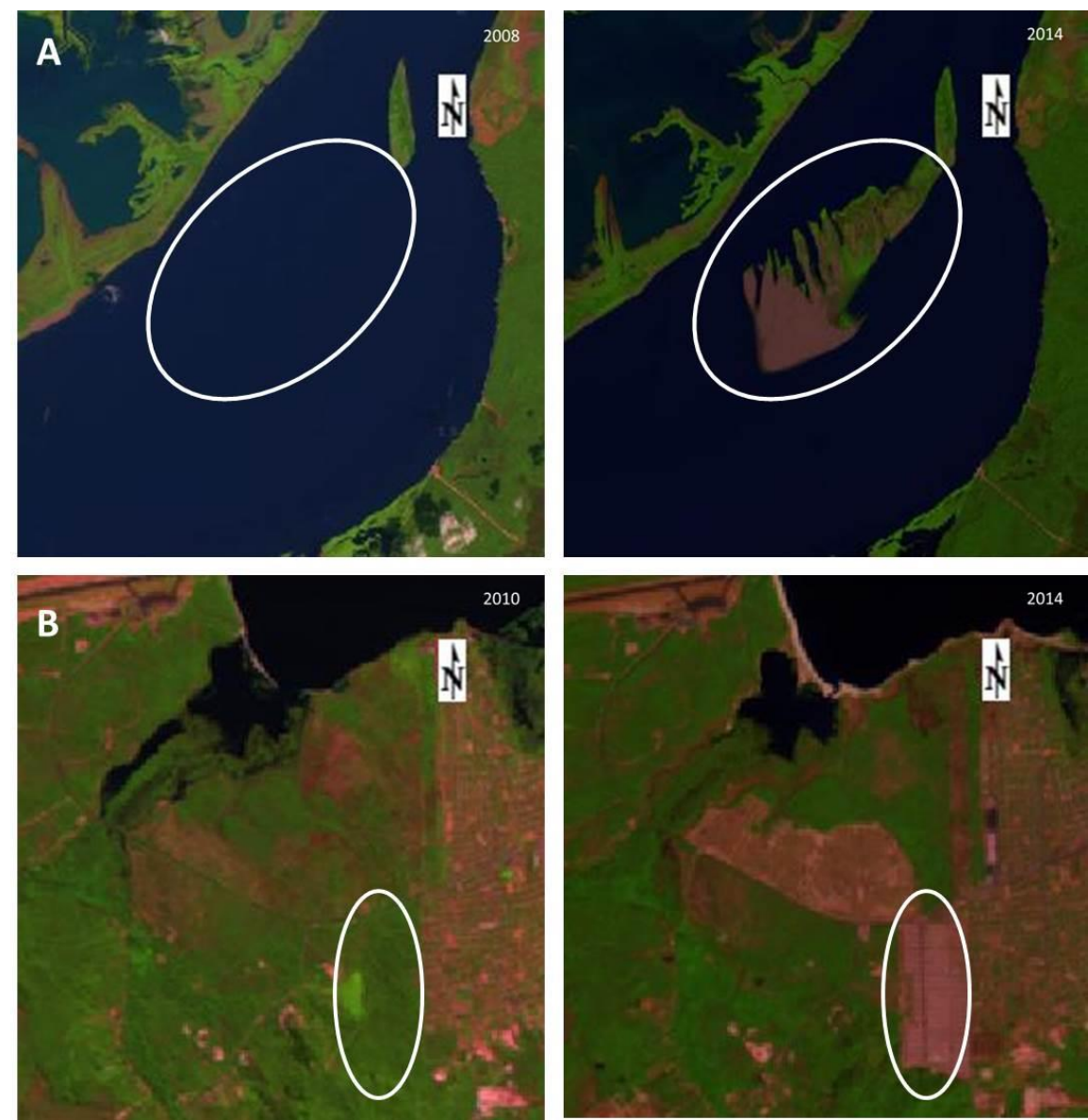

Figura 6: "Série histórica de imagens de satélite: Landsat" A - Formação de uma ilha no rio Amazonas, entre os anos de 2008 e 2014; B - Desmatamento em área urbana, para a construção de um loteamento de casas na periferia de Santarém, entre os anos de 2010 e 2014.

Fonte: De autoria própria.

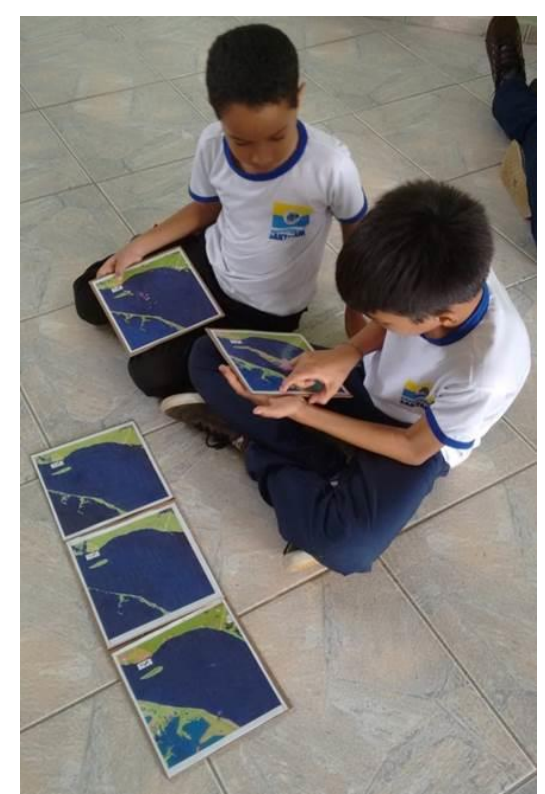

Figura 7: Alunos da Escola Fluminense brincando com o jogo de geoprocessamento "Série histórica de imagens de satélite: Landsat". Fonte: De autoria própria.

Revbea, São Paulo, V.11, № 2: 313-323, 2016. 
O contato com o meio científico é, também, outro fator importante na formação dos alunos. Uma vez que estes serão nossos "futuros cientistas", que poderão ajudar a conservar o meio ambiente. Koeppe, Borges e Lahm (2014) defendem que é fundamental a reformulação do ensino de ciências. Foi observado um grande interesse por parte dos alunos na abordagem sobre a temática de ciências. Além disso, os alunos se mostraram muito curiosos em conhecer o Laboratório de Geoprocessamento do CIAM, espaço onde são feitos os estudos ambientais e o uso de geotecnologias. Reforçando que, "laboratório de geoprocessamento" foi uma das palavras utilizadas no jogo de "Memória de geotecnologias", como uma maneira de fomentar a curiosidade dos alunos para esse tema.

O uso livre de programas e de dados de geoprocessamento é uma alternativa interessante para escolas da rede pública de ensino, já que a falta de programas de geoprocessamento tem sido apresentada como um dos principais gargalos no ensino de geotecnologias, como exposto por Correa; Fernandes; Paini (2010). De uma forma geral, a metodologia proposta no presente artigo se mostrou bastante visual e interativa, e obteve atenção e interesse dos alunos. A metodologia foi eficaz na transmissão de conhecimento sobre a importância da conservação dos recursos naturais. As práticas de educação ambiental e o uso do geoprocessamento são uma maneira valiosa de mobilizar a sociedade, na busca de um equilíbrio ambiental (Wrublack et al., 2014). Já Guimarães \& Cardoso (2014), acreditam que, somente a educação ambiental, pode ajudar a nossa sociedade a enfrentar a crise socioambiental atual.

\section{Conclusões}

O uso de jogos de geoprocessamento se demonstrou uma metodologia adequada para o ensino do uso de geotecnologias aplicada aos estudos ambientais, para alunos do quinto ano da rede de ensino público. Se mostrou uma metodologia de baixo custo de implantação e com boa aceitação entre professores e alunos. Essa metodologia pode ser aplicada em escolas da rede pública e privada de ensino, com diferentes temáticas e abordagens.

\section{Agradecimentos}

Á equipe da Secretária Municipal de Educação (SEMED), à Secretaria de Meio Ambiente (SEMMA) e ao Centro de Informação e Educação Ambiental (CIAM), todos do município de Santarém, pelo apoio e recurso logístico, que foram indispensáveis à elaboração e execução deste projeto. 


\section{Referências}

CORREA, M.G.G.; FERNANDES, R.R.; PAINI, L.D. Os avanços tecnológicos na educação: o uso das geotecnologias no ensino de geografia, os desafios e a realidade escolar. Acta Scientiarum: Human and Social Sciences, v. 32, n. 1, p. 91-96, 2010.

GUIMARÃES, M.; CARDOSO, C. Dos desertos geográficos a desertificação da vida... a Educação Ambiental em tempos de crise Revista Eletrônica do Mestrado de Educação Ambiental, v. 31, n. 1, p. 324338, 2014.

ANDRADES-FILHO C.O.; RIBEIRO B.M.G. Jogo do trunfo - satélites \& sensores: uma nova cartada no ensino de sensoriamento remoto. Revista Brasileira de Cartografia, v. 66, n. 4, p. 717-727, 2014.

EARTHEXPLORER. Imagens Landsat. Disponível em: $<$ http://earthexplorer.usgs.gov/>. Acesso em: 2 mai. 2016.

IBGE - Instituto Brasileiro de Geografia e Estatística. Arquivos shapesfile. Disponível em: <http://www.ibge.gov.br/home/>. Acesso em: 2 mai. 2016.

KOEPPE, C.; BORGES, R.; LAHM, R. O ensino de ciências como ferramenta pedagógica de reconstrução das representações escolares indígenas. Ensaio Pesquisa em Educação em Ciências, v. 16, n. 1, p. 115-130, 2014.

QGIS. Programa de geoprocessamento de uso livre. Disponível em: $<$ http://www.qgis.org/en/site/>. Acesso em: 2 mai. 2016.

SANTOS, J.M.; LAHM, R. A.; BORGES, R. M. R. Avaliação de Um Estudo de Biomas Brasileiros Mediante Sensoriamento Remoto: contribuições à formação de professores de Ciências. Revista de Educação em Ciência e Tecnologia, v. 2, n. 3, p. 83-105, 2009.

SILVA, C.N.A cartografia em sala de aula na explicação do espaço geográfico. Acta Geográfica, v. 7, n. 15, p. 55-68, 2013.

SILVA, E.V.; RODRIGUEZ, J.M.M. O ensino da geografia física: práticas pedagógicas e perspectivas interdisciplinares. Revista Equador, v. 3, n. 2, p. 38-50, 2014.

WRUBLACK, S.C. et al. As ferramentas de geoprocessamentos como recurso didático e suas possíveis contribuições para a educação ambiental. Revista Eletrônica do Mestrado de Educação Ambiental, v. especial, p. 201-213, 2014. 